\title{
Professional Health Sociologists and the Crisis of the Italian Health System: A Pilot, Exploratory Study within Mental Health and Addiction Departments through an Electronic-DELPHI
}

\author{
Pietro Paolo Guzzo ${ }^{1,2,3, *}$, Paolo Ugolini ${ }^{4}$ \\ ${ }^{1}$ School of Medicine, Sociology Professor, Bari University, Italy \\ ${ }^{2}$ Board of Directors of the Italian Society of Health Sociology (S.I.S.S.), Istituzione Minguzzi, Via Sant'Isaia, Italy \\ ${ }^{3}$ Observatory of Addictions, Local Health Authority of Cosenza, Via Medaglie d'Oro, Italy \\ ${ }^{4}$ Mental Health and Addiction Department, Coordinator of the Epidemiological Observatory, Local Health Authority of Romagna, Italy
}

Copyright $\mathrm{O} 2016$ by authors, all rights reserved. Authors agree that this article remains permanently open access under the terms of the Creative Commons Attribution License 4.0 International License

\begin{abstract}
This qualitative, pilot and exploratory study ${ }^{1}$ is part of an ongoing research project conducted by Società Italiana di Sociologia della Salute, (Italian Society of Health Sociology, hereinafter SISS) ${ }^{2}$ including academic and professional Italian health sociologists. The Literature on interprofessionalism/managerialism and the various roles of these health professions as "boundary spanners", gate-keepers and mediators, is still lacking in relation to the Italian Healthcare System (Servizio Sanitario Nazionale, hereinafter $S S N$ ) and its prolonged poli-crisis, from the point of view of Italian Health Sociologists employed within the SSN. In particular, in Italian Literature, empirical study does not exist on the representations and perceptions of interprofessionalism within this field. The aim of this qualitative essay is to present a counterpoint in the form of an explorative pilot study focused on a group of 17 Italian Professional Health Sociologists working in Mental Health and Addiction departments in the SSN. Here we consider the Professional Italian SSN Sociologist as an agent of change in the SSN transformation plan, and as a vehicle for interprofessionality.
\end{abstract}

Keywords Sociologist, Italian Health Care System, Crisis, Agent of Change, Interprofessionality, Electronic Delphi, Pilot Study

1 An earlier version (ESA-1634) of this paper was presented in the 11th European Sociological Association Conference (ESA 2013), held in Turin (Italy) 28-31 August 2013.

2 Founded in 2002, the SISS is committed to delivering wider social and legal recognition and protection to the health sociologist profession, in academia and in the professional filed. For more information go: $\mathrm{http}: / / \mathrm{www} \cdot$ sociologiadellasalute.org/

\section{Introduction}

This is a qualitative, exploratory pilot study using electronic Delphi (e-Delphi) method with The Nominal Group Technique (NGT) to develop a possible model to guide health professional sociologist working in the Italian Healthcare System (Servizio Sanitario Nazionale, hereinafter SSN) becoming the glue and vehicle of inter-professionality. In Italy, as Internationally, there is the growing push toward interprofessionalism/managerialism [1-2] and we find a similar plasticity of boundaries between health professions [3]. These trends have also affected the vicissitudes of the Professional Health Sociologist within the Italian Health Care System since 1978. The struggle for interprofessional repositioning and the search for new spaces of action for these Professional Sociologists in relation to other SSN professions (i.e. economists, managers, doctors, statisticians, social workers) is related to and part of the long SSN poli-crisis (economic, organizational and representative of the systems disconnect from the "life world" and the real needs of system users-citizens [4]. So what are the perceptions of Italian Professional Health Sociologists working in this time SSN crisis? How do they experience professional repositioning? What roles do they carry out inside and outside of the boundaries of the SSN? To answer these questions, we conducted a pilot, exploratory study using the Electronic-Delphi method [5], through e-mail correspondence between researchers and research subjects (17 Italian SSN Professional Sociologists) working in Mental Health and Addiction departments in the regions of Calabria (Southern Italy) and Emilia Romagna (Northern Italy). These experts point to a need for restructuring and stabilization within the field, with a particular reference to the testimony of Professional Sociologists active in the 
mental health and addiction departments of these two profoundly different regions of Italy.

\section{A Brief Literature Review}

We begin with an overview of related studies. The first, an international debate on new forms of interprofessionalism /managerialism [1-3] and the role of "boundary spanners" such as social workers, doctors, managers, etc. [6-9]. And then we will look at Italian literature related to SSN crisis [10-12] and the transformation of roles for professional health sociologists working within the various services that comprise the Italian SSN. Within the predominant international research studies [13-15] "boundary spanners" are defined as professionals who play a pivot role in promoting interprofessional collaboration, by placing themselves on the border (organizational, professional and disciplinary) between two or more systems with conflicting aims and expectations; and there is further research on the particularly roles of "boundary spanning" Italian sociologists. By acting as an intermediary, the SSN sociologist may become a boundary spanner between vertical borders (executives, managers and care providers) and horizontal borders (doctors, nurses, economists, statisticians, psychologists, etc.), by adopting various repositioning strategies. In this way, within the SSN crisis, these sociologists also act as agents of inter-professionalism.

In 2013 the SSN was comprised of 688 sociologist managers and around 300 associates, of which over $10 \%$ were involved in border or irregular sociological careers. In Italy, these professionals play many key roles. They are planners, evaluators and agents of integration between social and health care services, «actor-sensors»[16] and the primary agents of change, sensing the need for innovation.

The Italian SSN [10-12] has historically faced three separate but interconnected crises, namely, the global financial crisis, the welfare crisis, and the SSN crisis. The interweaving of these crises reflects the recent cultural and socio-epidemiological changes in the health and lifestyle choices of citizens, which has in turn radically changed health and social policies in Italy as in the rest of Europe. After its institutionalization (1978-1991), the Italian SSN underwent continuous reform, reflected by the frequency of new measures implemented since 1990. In a significant way, this reform process was induced by the financial crisis and accompanied by growing co-payment mechanisms for citizens. These reform measures considerably changed many aspects of the health-care system, including the assessment of performance for professionals such as: physicians, nurses, administrative managers and those in technical fields belonging to the SSN such as: biologists, engineers, chemists, statisticians and health sociologists. Today, new demands for healthcare require health services to move their focus from hospitals to community care centers in the territory, and to correlate clinical systems with community systems. In Bertini's view [17-19], these diversified systems of regional welfare mix models of "hybrid" governance, and become even more relevant in relation to mental health and addiction services.

This study moves from historical studies about the SSN sociologist figure [20-25] to a previous SISS [26] publication from 2009 that specified two interconnected future dimensions of identity and the current professional practice for Italian Health Sociologists within the SSN. In Italian Literature we find several themes related to the field of Professional Sociology: 1) the role of "professional compass" between the be of professional identity and the do of professional practice [27]; 2) various activities related to professional sociology and articulated through applied and clinical sociology [28-32]; 3) the role of "sensor-actor of change" [16];4) the interprofessional dimension of contemporary replacement [33]. In particular Bertin [34], reviewing Panza [16], indicates how the contexts of action are areas in which specific, locally situated practices, programs and evaluations are developed. In relation to these developments, professional and academic sociologists play diverse roles based on their own individual competencies, which are a mix of scientific knowledge, personal and collective experience. There are however scarce empirical studies on the perceptions and representations of professional sociologists working within the SSN. The topic was addressed, only incidentally, by Galesi [35], in a broader research study for Perino and Savonardo [36] on the real possibilities of sociological knowledge and skills in the Italian labor market. Our research instead, focuses specifically on perceptions and representations of SSN sociologists in relation to the crisis and their activities within the SSN system. SSN sociologists use their skills (methodological, planning, design, research) for the purposes of interprofessional integration within organizational and institutional areas of social and health care services. They are intra-professional mechanisms of change (diversification, specialization) and interprofessionalism (vertical and horizontal exchange) in ways different than other SSN professions; though in some ways they are contiguous with economists, psychologists, statisticians and social workers. In this way the sociologist is a catalyst for interprofessionalism, situated in between social and health sectors (social-health integration at organizational, professional and institutional levels).

This study acknowledges the SSN Sociologist's role as a catalyst of sense making between users and operators of the SSN, as well as the "interprofessional glue" of knowledge and practice between different organizational units within the same SSN. This exploratory and pilot study, in the framework of the above-mentioned crisis of SSN transformation, identifies visions and models of interprofessionality through the lens of sociologists performing diverse social-health services with three macro functions: cognition, mediation, and evaluation [31]. As previously indicated, we specifically selected some active SSN sociologists from the departments of mental health and pathological addictions [9] in the regions of 
Emilia-Romagna and Calabria [37].

In all of the Italian studies on the field of Sociology, we find two salient aspects. First, two different identity experiences or "souls" within the field: performative-managerial [30], [31], and clinical-empathetic [28], [29], [38],[39]. Secondly, there are four major areas of inter-professional integration: design, evaluation, communication, prevention and networking. These refer to a variety of activities such as:

- The identification of health problems and associated needs

- The definition of areas of intervention and associated recipients

- The definition of organizational objectives and related evaluation tools and methods

- Integration, liaison and coordination of all services belonging to the activity involved

- Promotion, in particular in basic health districts, of joint practices, networks and networking (co-working)

- Collaboration with institutions

To explain the relationship between these two ways of being (managerial and empathetic) within professional sociology (reflective of its main branches: applied and clinical), it is useful to recall, the concept of interprofessionality as a field of collaborative practice and shared learning between varied health professionals [40]. Interprofessionality ${ }^{3}$ is a concept often overlooked by psychologists, but the Italian sociologist Ardigò [41-42] anticipated this concept as "concurrent jurisdiction". Here, the professional sociologist of the SSN is described not relative to psychologists, but emphasizes a key sociological function as an integrator and/or interprofessional glue. From the theory of Sainsaulieu [43] and Guzzo [33], we further distinguish the scope of agitated interprofessionalism within two spheres: care activities and organizational management.

Professional Sociologists, especially those practicing within Italian Health Care Organizations, can be identified by the multitude of activities they perform, and frequently there is no logical link between these activities as the field is

3 In general, we distinguish interdisciplinary («development of integrated knowledge in response to fragmented disciplinary knowledge» and interprofessionalism [43] that regards the connection «between two spheres of activity: training in collaborative interprofessional activities (processes and determinants), and [...] the development of a cohesive practice between different professionals of the same organization and the factors affecting them» [43, p.7]. Interprofessionalism is simultaneously a working method for action-intervention, and a process to address different crises within the SSN. It is not only a method of working and learning, but also a mixture (stock and flow) of relational, peer-oriented and useful, social and organizational capital for the re-programation of interventions; providing opportunities for critical reflection on the interventions of evaluation, diagnosis and social therapy. In this framework of interprofessional integration, sociologists can glue and catalyze interprofessionalism. As the crucial factors of reflection and mutual learning between different actors within social networks evolve, so to will the organizational and clinical networks that innervate co-working within the healthcare system. This interprofessionalism offers possible answers to complex problems through the construction of integrated solutions based on collaborative models to chart new territories and unite professional practice networks. On the interprofessionality limits see, especially, Hudson [46]. characterized by many approaches and theoretical paradigms.

Currently, over 688 executive sociologists are engaged within the SSN and occupy strategic positions in the current reform process. We can delineate their functions in four categories [44-45] (fig.1):

- Government (Directors of simple or complex operating units, Directors of health districts)

- Government-Exercise (Directing staff within Observatory/ Information systems, Quality/ Accreditation systems, Evaluation /Research systems, etc.)

- Exercise (Planners and Managers of local area networks, communications, environment, etc.)

- Clinical (Providing social therapy and clinical reports to patients, etc.)

Figure 1, visually articulates this summary in four main areas of organizational intervention, where the SSN sociologist, can work as a leader and functional supplement of experience, practice and skills capable of activating, facilitating pathways, and processing exo-endo organizational innovations.

In the following section we will look at the Italian National Health Care Crisis, and the specific "boundary spanner" roles sociologist have played as promoters of inter-professional collaboration inside and outside the SSN.

\section{Objectives}

This study has two main objectives. The first, of a general nature, observes the process of change in order to delineate good sociological practices in two areas: 1) The improvement of system governance and centralization of evaluation processes (government); 2) The creation of empowered citizens, institutions and communities by enabling active participation in health care processes (exercise).

There are two other specific objectives: 1) To detect connections between areas of practice such as governmentexercise, hybrid governance systems, epidemiological observatories/information systems and research, evaluation/programming, quality management systems, training and accreditation programs, activators/managers of network systems and communication/prevention networks; 2) To first check the general hypothesis of a broader theoretical scheme, according to which the Professional Health Sociologist acts not only as sensor-actor [16] but, more significantly, as an innovator and interprofessional glue [33] within the SSN 


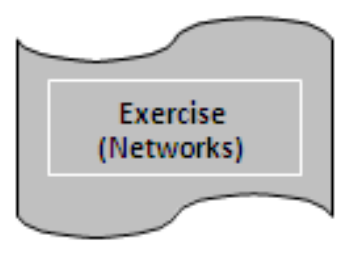

Social Research

Training
Design and Programming

Evaluation

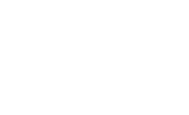
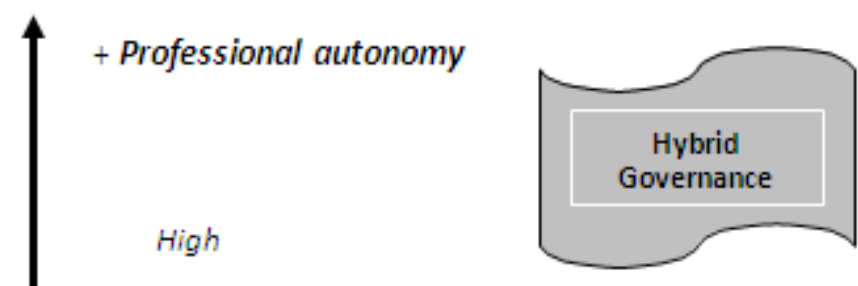

Organizational direction

+ intersubjectivity

+ Managing skills

- Support-advice

\section{Education and Health Communication}

\section{- intersubjectivity \\ - Managing skills \\ + Support-advice}

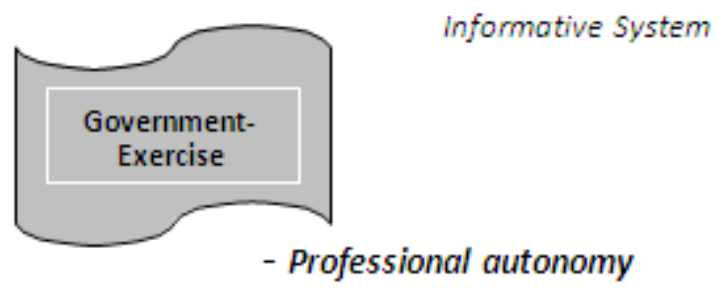

Observatories

Source: developed and adapted from Guzzo [33].

\section{Coordination and integration of Social and Health Care Organizations}

\section{Interfoce services}

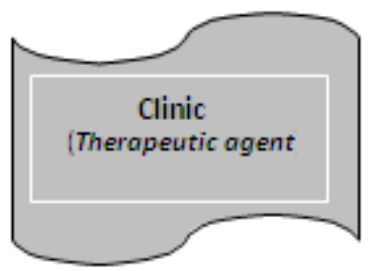

Figure 1. Macro-areas grid of innovation for the Italian professional sociologist working in SSN

\section{Methods}

\section{Ethics and Governance}

Formal ethical approval by the research ethics committee system was not required, according to Italian law, for this kind of study (i.e. a non-trial interview study without biomedical material or biomedical data). All interviewees gave their consent to recorded interviews and the use of written materials for research publication. Both Authors are trained in the social sciences (both are social scientists and sociologists), and all data was compiled and examined anonymously. Care has been taken to ensure that the findings presented here are not attributable to any of the participating individuals.

\section{Design}

We conducted this explorative, pilot research study between June and August 2013 using an electronic-DELPHI [47] method. We used e-interviews for data collection; e-interview is an on-line asynchronous research method in which the respondents use e-mail correspondence as a computer-mediated- communications tool, under the conditions of reciprocated anonymity as indicated in the DELPHI method. This e-interview process took the form of a discussion group with an asynchronous research method in which the discussion leaders emailed several open-ended questions to a group of respondents. A regular email discussion consists of only one round of questions, but in this e-DELPHI model, the discussion leader aggregates and analyses the initial responses before returning an overview of the results to the respondents ${ }^{4}$. The overview contained the

4 The two most popular online qualitative techniques are online focus groups and email discussions. Online focus groups are interactive qualitative group discussions that bear a strong resemblance to traditional focus groups but take place on the Internet. Email discussions, like online focus groups, are not bound by geographic location, which allows respondents to participate from the comfort of their own home or workplace. In addition, email discussions give respondents the freedom to participate in the conversation when it fits their schedule, which can be attractive 
emerging themes as well as the most interesting and polarizing responses to each question. Each respondent was then given the opportunity to react to the overview by confirming the results or by adding nuance to them. This procedure creates a sort of indirect interaction for respondents responding individually. During subsequent rounds, the discussion leader created new questions derived from the results of the initial e-interview, providing a deeper exploration of the opinions and attitudes of respondents. This added "virtual" interaction between respondents and researchers is what makes e-DELPHI more through than a simple qualitative summary. Relevant data was collected through the orderly and sequential exchange of e-mails between the researchers/interviewers and respondents. More specifically, this study uses a mixed methodology of e-research [48-52], following the schedule of DELPHI and the hierarchy of values from the Nominal Group Technique (NGT) $[53-54]^{6}$

Invitations to participate were sent by e-mail with an interview guide containing aims, objectives of the research and a working calendar for the two e-DELPHI rounds. The first interview guide included: a socio-biographic report card, a brief career summary or bio, specific skills and experience in relation to redesigning the SSN in the crisis, skills and experience related to mental health and addiction services, types of innovations to be performed in the four macro- areas of interventions within the SSN (see figure 1), roles in relation to the existing structures of the $\mathrm{SSN}$, as well as challenges and dilemmas related to the "boundary spanning" role (representation and identification).

\section{Sampling}

A panel of the experts interviewed and selected a purposeful and convenient sample of SSN sociologists for this study on the basis of their recognized expertise and interprofessional practice within the regional public health services of Emilia-Romagna ( 9 sociologists) and Calabria (8 sociologists).

The sociologists were invited to participate based on certain criteria: a) they demonstrated an interest in the research; b) they had been in their position for a least 5 years; c) they held an executive position in department of health care, mental or addictions services; d) $50 \%$ of the interviewees worked in Calabria and 50\% worked in Emilia Romagna. We based our purposeful selection on career analysis as well; please note that we have also included sociologists "on the border" (i.e. those not specifically employed as sociologists who work in the field and with these competencies). The sociologists were specifically

especially for busy respondents [55-56].

5 DELPHI is a well-known technique that provides structure to the communication among a group of privileged testers (or experts) in order to collect personal insights on predictions, hypotheses, etc.

6 The technique echoes the NGT, which Bezzi [57] called the "Hierarchy of Obliged Priorities", where the group is asked to collect ordinal values on previously selected indicators previously [53, p.341]. interviewed about their work experiences, particularly in relation to the taxonomy of sociologist macro-activities (as showed in fig.1) role and functions in the present crisis of the SSN.

The 17 SSN sociologists who participated (as shown table 1.) represented a range of experience and were between the ages of 43 and 65 . Table 1 shows relevant socio-demographic information about the sample. The panel of selected experts was interviewed in two e-Delphi-rounds using a system of anonymous codes (Delphi participants, or p).

Table 1. Summary sheet of e-Delphi participants (p) or interviewees.

\begin{tabular}{|c|c|c|c|c|}
\hline Code & Years & Sex & Region & $\begin{array}{c}\text { Years of } \\
\text { employment and } \\
\text { Departments }\end{array}$ \\
\hline$[\mathrm{p} .1]$ & 58 & $\mathrm{M}$ & Calabria & $31\left(^{*}\right)$ \\
\hline$[\mathrm{p} .2]$ & 44 & $\mathrm{~F}$ & Calabria & $12\left(^{*}\right)$ \\
\hline$[\mathrm{p} .3]$ & 46 & $\mathrm{~F}$ & Emilia Romagna & $22\left(^{* *}\right)$ \\
\hline$[\mathrm{p} .4]$ & 45 & $\mathrm{~F}$ & Emilia Romagna & $14\left(^{\wedge}\right)$ \\
\hline$[\mathrm{p} .5]$ & 60 & $\mathrm{M}$ & Calabria & $36\left(^{\wedge}\right)$ \\
\hline$[\mathrm{p} .6]$ & 62 & $\mathrm{~F}$ & Emilia Romagna & $40\left(^{*}\right)$ \\
\hline$[\mathrm{p} .7]$ & 52 & $\mathrm{M}$ & Calabria & $20\left(^{* *}\right)$ \\
\hline$[\mathrm{p} .8]$ & 48 & $\mathrm{M}$ & Calabria & $09\left(^{*}\right)$ \\
\hline$[\mathrm{p} .9]$ & 56 & $\mathrm{~F}$ & Calabria & $32\left(^{* *}\right)$ \\
\hline$[\mathrm{p} .10]$ & 46 & $\mathrm{~F}$ & Emilia Romagna & $26\left(^{\wedge}\right)$ \\
\hline$[\mathrm{p} .11]$ & 46 & $\mathrm{~F}$ & Emilia Romagna & $16\left(^{*}\right)\left(^{* *}\right)$ \\
\hline$[\mathrm{p} .12]$ & 62 & $\mathrm{M}$ & Calabria & $37\left(^{*}\right)$ \\
\hline$[\mathrm{p} .13]$ & 53 & $\mathrm{M}$ & Calabria & $25\left(^{\wedge}\right)$ \\
\hline$[\mathrm{p} .14]$ & 50 & $\mathrm{~F}$ & Emilia Romagna & $16\left(^{*}\right)$ \\
\hline$[\mathrm{p} .15]$ & 65 & $\mathrm{~F}$ & Emilia Romagna & $40\left(^{* *}\right)$ \\
\hline$[\mathrm{p} .16]$ & 60 & $\mathrm{M}$ & Calabria & $35\left(^{\wedge}\right)$ \\
\hline$[\mathrm{p} .17]$ & 43 & $\mathrm{~F}$ & Emilia Romagna & $15\left(^{* *}\right)$ \\
\hline
\end{tabular}

Note: $(*) \mathrm{AD}=$ addiction departments $(* *) \mathrm{MHD}=$ Mental Health Department, $(\wedge)$ Other $\mathrm{p}=$ participant to interview.

\section{Data Collection and Handling}

The two researchers, as interviewers, approached potential participants, invited their interest, informed them of the study and then e-mailed a copy of interview guide to those potential participants who demonstrated on interest in the research. Those who agreed to participate in the study were asked to complete the consent form, and made e-Delphi arrangements. All participants were advised that they could withdraw from the study at any time. The response rate for those who meet the criteria was $100 \%$ and none of the participants withdrew from the study.

In the second electronic Delphi-round interviewees were asked to ponder and graduate a series of possible answers, and then to establish a hierarchy (from 1 to 10) among themes and subjects identified by the researchers from the previous rounds. The participants' final task was to ponder another set of a priori interventions, a set not previously indicated by the researchers (tab.2). The interviews were 
then analyzed using an ethnographic-narrative method, and interpreted with a generative approach in order to identify concepts relevant to the theoretical framework mentioned above.

\section{Data Analysis}

E-interview questions were open-ended and semi-structured to promote profound and diverse responses. The interview was analyzed for emerging themes related to the pertinent literature, and then coded according to those themes using the Nueman [58] three phase coding system. During the first phase of coding, the first author-researcher performed an initial scan of the data, highlighting words or phrases used by the participants and locating initial themes. Successively both researchers identified jointly the core themes to the aims of the study, connecting themes and focusing links in the data. In the final phase, the first researcher reread the data and assigned excerpts to illustrate emerging themes. All coding was double-checked to ensure accuracy. Using a thematic analytical approach [59], the material was coded and re-coded in the second and third readings, to form an initial list of categories around which to organize the data. As data saturation was assessed, all transcriptions were reviewed to form an overall impression of the material. Some of these categories corresponded directly to the themes in the interview guide, while others constituted additional categories. For instance, all descriptions of challenges experienced by practicing sociologists were first coded in one common category 'challenges', while in subsequent readings, such broad codes were refined and organized into a set of coherent and distinct categories containing the different types of challenges [60] In consecutive readings of the material, codes and data were checked against each other to ensure correspondence. Specifically, to confirm whether all analytically interesting aspects of the material were covered in the codes and whether the coding of units of text made sense in the context in which the units appeared in the data material [61]. The administration of two distinct sets of questions was interspersed within the relative phases of study and reflection, and the results of this generative procedure (encoding/recoding) is further described in Section 4, Table 2 and Figure 3.

\section{Results}

From the discourse of these Professional Sociologists (not only those within mental health and addiction departments), we have generated a list of emerging themes and key issues (tab.2). We found homogeneity and specificity (tab.3, fig. 2)

Between the priorities of professionals who operate in these geographically distant regions (Calabria and Emilia Romagna); those whose mixed and profoundly different welfare systems are not only diverse due to geographical location, but because they have very different social and institutional histories (tab.3). It is surprising to observe how the themes and issues discussed were so similar despite their very different contexts. In figure 3 we have compared the codes most frequently revealed by both sets of respondents.

Table 2. The score of respondents on the macro-areas investigated

\begin{tabular}{|c|c|c|}
\hline Ranking & $\begin{array}{c}\text { Description of the macro-area selected by } \\
\text { respondents }\end{array}$ & $\begin{array}{c}\text { Points } \\
\text { assigned }\end{array}$ \\
\hline$\# 1$ & $\begin{array}{c}\text { Quality Management Systems/Training and } \\
\text { Accreditation }\end{array}$ & 23 \\
\hline$\# 2$ & $\begin{array}{c}\text { Activator/Manager of Network and } \\
\text { Communication/Prevention }\end{array}$ & 20 \\
\hline$\# 3$ & Evaluation/Programming & 21 \\
\hline$\# 4$ & $\begin{array}{c}\text { Epidemiological Observatory/Information System } \\
\text { and Research }\end{array}$ & 19 \\
\hline$\# 5$ & "Hybrid" Governance systems & 10 \\
\hline$\# 6$ & Government Exercise & 7 \\
\hline
\end{tabular}

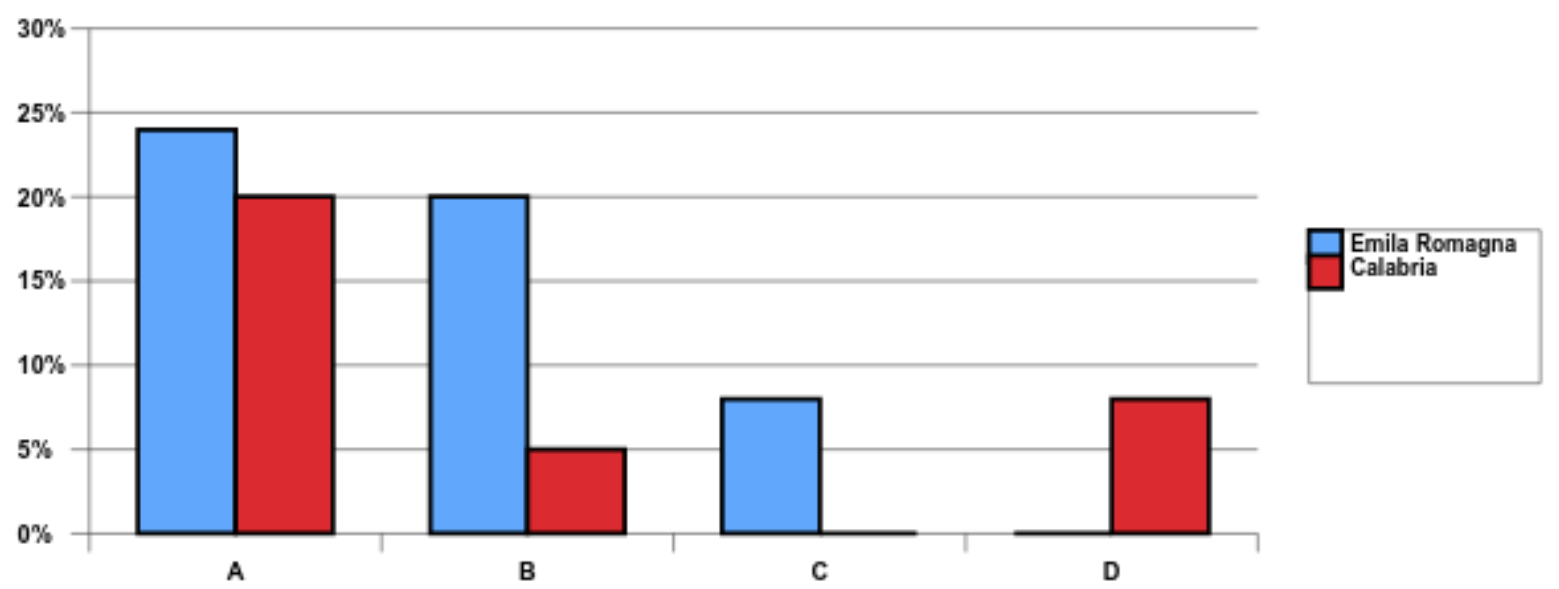

Legend:

(A)Society Profile with Socio-Sanitary Cutting to meet Societal Needs and Demands

(B)Optimistic Vision of a Reformed SSN

(C)The Value of Institutionaland "Proximity" Communications

(D)Negative Experiences with Integration

Figure 2. Commonalities and differences between the two classes of regional respondents 
Codes $A$ and $B$ are very frequent in both the first and the second set, the differences are revealed in codes $C$ and $D$ respectively, emphasizing the need for a functional network between individuals, structures and institutions in EmiliaRomagna, as well as a need for a positive means of integration in Calabria.

Table 3. Two Distant Regional Welfares types: Emilia Romagna and Calabria

\begin{tabular}{|c|c|c|}
\hline $\begin{array}{l}\text { Type of } \\
\text { Welfare }\end{array}$ & $\begin{array}{l}\text { Regions that } \\
\text { belong to the } \\
\text { welfare system }\end{array}$ & Characteristics \\
\hline $\begin{array}{c}\text { Generalized } \\
\text { and generous }\end{array}$ & $\begin{array}{l}\text { Friuli V.G., } \\
\text { Toscana, } \\
\text { Lombardia, } \\
\text { Veneto, Emilia } \\
\text { Romagna }\end{array}$ & $\begin{array}{c}\text { Mixed structured with the presence of } \\
\text { some signals of orientation toward the } \\
\text { social level, the expanded offering of } \\
\text { traditional services and guidance toward } \\
\text { community health centers in the territory, } \\
\text { is fairly cohesive with relatively low } \\
\text { social risks }\end{array}$ \\
\hline $\begin{array}{c}\text { Minimal and } \\
\text { High Social } \\
\text { Criticality }\end{array}$ & $\begin{array}{c}\text { Puglia, Calabria, } \\
\text { Campania, } \\
\text { Sicilia }\end{array}$ & $\begin{array}{c}\text { Weak presence of all players (public and } \\
\text { private) and a lack of orientation signals } \\
\text { towards subsidiarity. It appears generally } \\
\text { that there are few present offerings, and } \\
\text { the society's recent expansion presents } \\
\text { high social risks. }\end{array}$ \\
\hline
\end{tabular}

Source: adapted from Bertin [19]

\subsection{Emerging Themes}

Respondents focused their discourse around four main themes:

- The perception of the SSN crisis

- The repositioning of the sociologist within healthcare organizations compared to other professions in the SSN (such as doctors, economists, statisticians, ITs)

- The type of interpersonal relations (conflicts, alliances, etc.) within various departments (especially those for addictions and mental health)

The need to align University Education with the real world professional practice of Professional Health Sociologists working in the public health sector (i.e. not distributing seemingly qualifying degrees for studies that do not reflect the field)

\section{Delphi Round One: diverse perceptions of the SSN crisis}

a. As a deficit in community planning and sharing:

"Considering the current "crisis" of the programs (Local Implementation Plans (P.A.L.), Area Planning (PdZ), Implementation Plans, etc.) »[p.10]

b. As an overload of self-referencing organizations:

«The set of often disjointed operational realities, are not interrelated, and unfortunately are self-governing with selfreferencing rules and little attention to user satisfaction " [p.8]. c. As an organizational and economic failure:

«Now that the welfare crisis poses a number of thoughts and revisions on the economic sustainability of management models to be adopted » [p.8]

d. As a check on system loss:

«Within the territorial services [...] the different services $[\ldots]$ do not talk to each other » [p.17].

The professional repositioning of The Sociologist: conflicts, alliances and inter-professionalism

On alliances and interpersonal conflicts, respondents are divided.

«[...] in the 80's, the profession "sociologist" was largely unknown, and consequently was often assimilated to a social worker or psychologist by system users and other operators $\gg[\mathrm{p} .12]$

«Every sociologist with significant years of experience can really make a difference in the health system, but this has clashed and collides with other professional figures in the health sector who are more numerous. Starting with doctors who have seen and do see, major contract awards and status, leading them to higher positions and negative biases. Today this battle still exists and lies were "various unions and associations" can have no effect on the legislature which has the power to professionally recognize and raise the status of the sociologist. The professional role we occupy is a personal achievement that we have always had to argue, in any case, with stronger professional "categories" of us. But, in the end they had to acknowledge, that our skills are not their skills and vice versa!» [p. 8]

«I personally believe it is not a problem or conflict of rights, or "birthright"; also I do not deny the asymmetries of power and spaces for "visibility"» [p.15].

Two macro-areas (evaluation/planning, systems management quality/accreditation and training) are the scene of clashes with other professionals of the SSN:

«It is a field already occupied by many disciplines and a terrain for all health disciplines. You have to see if you can hold the "competition" through competence, and if for example you cannot, also improve the curriculum and training in these particular aspects». [p.11]

As you see, it would be most desirable if the sociologists' activities were carried out as part of a team:

«Do the technical $[\ldots]$ as a team. [...]» [p.15]

This versatility of characteristics, skills and abilities is in fact difficult to assimilate in one person. The team can also be 'virtual', i.e. be the result of coordinating a network of guidance centers in different locations, each with a specific vocation or a precise target. 
For others still, the conflict is only residual, confined to the macro-area of clinical sociologist competence:

«[...] It does not highlight any kind of conflict, only opportunities for alliances and future designs. In the clinical context, sociologists may conflict with the growing number of psychologists who think they can do everything, and nurses who specialize in counseling» [p.4].

Others, finally, without diminishing the scope of conflicts in the SSN, aim for interprofessionality [17] as a form of inter-alliance, capable of engaging in the analysis of health care organizations, sociologists, economists and doctors:

«Training in sociology (for me Sociology of Organizations) directs many towards a reading of the organization, processes, values and use the tools to govern, from legal to economics to relational, without identifying only one of these. This is a distinction in comparison to colleagues with different training and approaches such as graduates in economics or medicine, or those commissioned as government extensions.» [p.10]

«Our areas of alliance are in social research and evaluation, the ability to work as a team, multiple perspectives on problems. [...] We have moved ahead in our careers because of strong historical figures, and daily we have to quarrel with social workers, psychologists, communication experts, statisticians (here we have a few cards, but in the area of research we have distinctive competencies) » [p.15].

«The hybrid governance system <evokes> the governing of the network and interprofessionality» [p.7]

«The mindset of the sociologist is to analyze health issues from multiple points of view, even through other disciplines, and be able to draw connections between them» [p.12]

$\ll<$ One of his gifts $>$ is the capacity of an overall vision that sees beyond multi-professionalism, promoting synergistic actions» $[\mathrm{p} .10]$

Delphi-Round Two: interprofessionality

Some respondents believe reports of interprofessional cooperation differentiated by macro-areas of expertise:

«Doctors have very strong epidemiological skills (much more than sociologists), and statistics proficiency is exercised by many professionals (at a much higher level than that of sociologist). Evaluative skills are less fertile soil in professionalism, and this is an area where many are exercising with low skills, skills related to high quality. Many operators, administrators, doctors, nurses and educators have competences in this area, information system skills. In the area where sociologists might best serve, we often find service managers ready to entrust this task to other professionals. Organizational skills are those skills that have good effects if you connect to all the other skills listed above, if not the sociologist is not responsible for service/operating unity $»[\mathrm{p} .11]$

«I think that the future is in the connections that help realize new products in which all partners in the process can be recognized, knowing that the results are not reached alone. This is also a way to put users and the user satisfaction at the center» [p. 11]

The interdisciplinary perspective is saturated in the "mantra" of social health system integration:

«The cultural background of the sociologist, allows him/her to relate on many levels: communication, planning, action research, evaluation etc. [...] The mediation function allows, in a setting characterized by the negotiation of objectives and the planning of interventions and strategies, the creation of an effective synergy of skills and responsibilities in an interdisciplinary integration that represents added value in the health care context $»[p .3]$

«In the health sector the contribution of an executive sociologist can be decisive in governing the internal complexity of service organization. In particular, his/her role can be decisive for all those often disjointed social and health organizational realities in the pursuit of performance with medium to high quality standards, that should instead maintain interdependence and a shared vision. Business operating units increasingly integrate health system functions with social issues (social health system integration). Where this occurs, the degree of appropriate performance is high. In this field the sociological activities of the responsible manager emerge as a whole, and take the form of a set of consistent and coordinated actions aimed at implementing the objectives of socio-regional and corporate health policies » $[\mathrm{p} .8]$.

\section{A More Relevant University Education}

Some respondents emphasized concerns about University Education, which still seems too far from the real world professional practice of Professional Sociologists and the corresponding needs of the labor market.

«A revision would be desirable, in key utility and marketability of many "Masters Degrees" of dubious theoretical strength, a practice and culture, which could represent a qualitatively important commitment to the association of sociologists». [p.6]

«Allow me a general reflection on university courses...the drama is there in the absolute emptiness, inconclusiveness and lack of knowledge useful to the profession. I saw graduates in political science and social policy-making declare themselves "sociologists"... they have not made any examination 
of statistics and social research techniques... what will they bring to the work? We would like maybe to mimic the psychologist who mimics the doctor? » [p.15]

\section{Discussion}

Recalling fig. 1 and the four areas of reference, there is a clear predominance of the functions under "governmentexercise" and a generic or non-existent reference to clinical functions (including potential clinical functions). Signaling the value of the environment context, first as knowledge of the problem and related resources (primarily social networks), and then as the ability to perform bottom-up social planning; these are the elements which emerge most clearly within general health care, mental health care and treatment for pathological addictions. Another interesting trend emerged from our pilot study in the analysis of responses to item quality. Participants were asked to weigh the areas highlighted by the first questionnaire (where 10 points were assigned as shown in fig.1), and it seems that priority must be given to the technical areas (specialized and targeted) held by sociologists within different levels of government-exercise organizations, mainly those in roles of staff direction. This does not however take away the significance of $20 \%$ of those who are activators /managers of network systems and communications, and therefore in direct contact with problems and practice.

Among the responses, we detected at least four different meanings for, or perceptions about the crisis according to the interweaving mentioned at the beginning:

- Crisis as failure (organizational, economic)

- Crisis as necessary for transformation (of the system)

- Crisis as loss of identity (personal, professional)

- Crisis as loss of control (over the system)

In summary, professional sociologists in Italy have experienced two distinct phases of interprofessionality in correspondence to the SSN development cycle. In the first and institutionalized phase of SNN (1978-1991) The Sociologist played mainly an exploratory function in relation to underlying social problems in the construction of health care facilities and services (interprofessionalism type A, vertical boundary spanning). In the current reform process (1992-todate), the same professionals have instead assumed a more organizational function within the workings of the $\mathrm{SSN}$; providing managerial skills and pointed interventions (interprofessionality type B, horizontal boundary spanning). Hence the transition, in our framework, from Clinical and Exercise areas to Government and Government-Exercise areas. The goal is not to merely adapt the role of sociologists to social practice or conflict management (endo/exo organizational, individual, inter and intra-professional), but rather to "steward" new organizational and capital resources. The Professional Health Sociologist is a director and selector of information, decisions and projects, an actor and sensor of change induced by the SSN crisis, and in this sense, a vehicle and glue for the roles and strategies of government-exercise and interprofessionality, concretely acted out in different territories (physical, organizational and symbolic) to promote health and cure disease.

\section{Strengths and Limitations of the Study}

This research study has two major strengths. First the subject addressed, the qualitative analysis of the perceptions and representations of Professional Health Sociologists in relation to the SSN crisis and the complexity of their role inside that system has never before been investigated in a national or international context. Secondly, the methodology we adopted, the electronic-DELPHI conducted through e-mail exchanges scheduled between the researchers and research subjects, provided valuable time for consideration and adjustment during the research period. The e-Delphi manages to overcome the typical disadvantages of the traditional Delphi Method (by surface mail) such as, the time and expense of designing paper and pencil questionnaires, mailing surveys, compiling responses, and follow up through multiple iterations. In addition, e-DELPHI promotes communication and ongoing review of hypotheses and theories among researchers and research subjects.

There are likewise two main limitations of the study. First, the purposeful selection is small and thus the results are less applicable to the other contexts. Secondly, the inherent technical limitations of e-DELPHI method, such as, participant recruitment and selection, sample size, instrumentation and data collection, as well as the lack of non-verbal communication ques. This last lack can negatively impact on the quality and depth of the data [55-56]. In addition, the anonymity inherent in online communications requires that researchers never take for granted that the respondent really is who he or she claims to be [62].

Some of the researchers' choices have partially mitigated these limits. First the dual characterization of the study as exploratory-pilot research in order to explore new issues, and test tools for a more extensive future study on the perceptions and representations of Italian Professional Health Sociologist. Secondly, special care was taken to handle the e-DELPHI as an unobtrusive and anonymous opportunity to enhance the research capital stock. This method seems to improve comprehension, and ease the adjustment of procedural problems while maintaining the experts' interest throughout successive iterations [63-64].

\section{In Conclusion, an Heuristic Model}

The results of our study show that the professional SSN Sociologist has undergone a process of critical insertion 
within various health care organizations in Italy for more than 30 years. Regionally, the results of this process vary greatly. The opinions of and suggestions made by the sociologists interviewed in relation to all four functions and the macro-areas described above are vastly diverse. The readings on the SSN crisis were useful as well since these emerging themes were not considered short term, but systemic by those interviewed. The vicissitudes of the SSN are woven tightly to the repositioning of these professional health sociologists, and truly those sociologists who are permanently employed in management positions by public health agencies, or those carrying out regulatory functions. In fact, since the formation of the SSN (1978-1991) leading up to today's phase of crisis and continuous reform (1992 to date), the Professional SSN Sociologist has gradually assumed more diverse roles and organizational functions within and without health institutions. Despite difficulty and profound hardships, The Professional Health Sociologist became an explorer and connector in the participatory processes of the public health care system in the first phase of SSN formation, as well as a promoter of interprofessionality - a special type of boundary spanner- in successive stages.

To summarize, we present a heuristic model (figure 3) derived from analysis and reflection on the interviews. In this model, the Professional Health Sociologist is considered as both an actor-sensor and catalyst-glue of interprofessionalism.

In our theoretical framework (figure 3), the SSN Sociologist is an intermediary of sense/meaning not only inside the SSN, but also within the entire health care system and "Life World". A sense-mediator sociologist [65] is one who blends the systemic meaning of the health care system with the interpersonal meaning created in the relationship between system users (operators and recipients) by grasping and translating the needs of citizens to the health care system itself. It regards the communication capacity, facilitating sense-construction processes and intervening in relational dynamics among social actors (at the macro, meso and micro-level).

Through this lens, the SSN sociologist appears to become a sense-meaning catalyst [65] between the health system's consumers and operators and the "glue" of interprofessionality throughout organizational units of the SSN. At the same time, this sociologist manages to be an attractor and catalyst for diverse and complementary skills around a service or shared project of intervention (for social innovation in health care, in a reticular logic of co-working). To do this the sociologist must play multiples roles: relayer of information and decisions, programmer, evaluator, network enabler, broker, etc. He or she uses many skills to develop concepts, identify new health needs, and fathom the social determinants of new inequalities, like the deficits in access related to gender and ethnicity. He or she moves from identifying as a sociologist "director" of simple or complex units, to a "technical" sociologist dealing with assessment and/or information systems, to a "mediating" sociologist navigating conflicts along the way, even to a "therapeutic" role within clinical sociology. We can clearly see a wide range of positions available to sociologists within SSN. This flexible identity however, also illustrates a strong and consistent weakness. Namely, that the role of professional sociologists leans toward intercepting the flow, sense-making [30] and negotiation processes between organizations, professionals and system users-citizens (oriented by personal experience); activities which we find more and more at the center of SSN reform today [31] (fig.2).

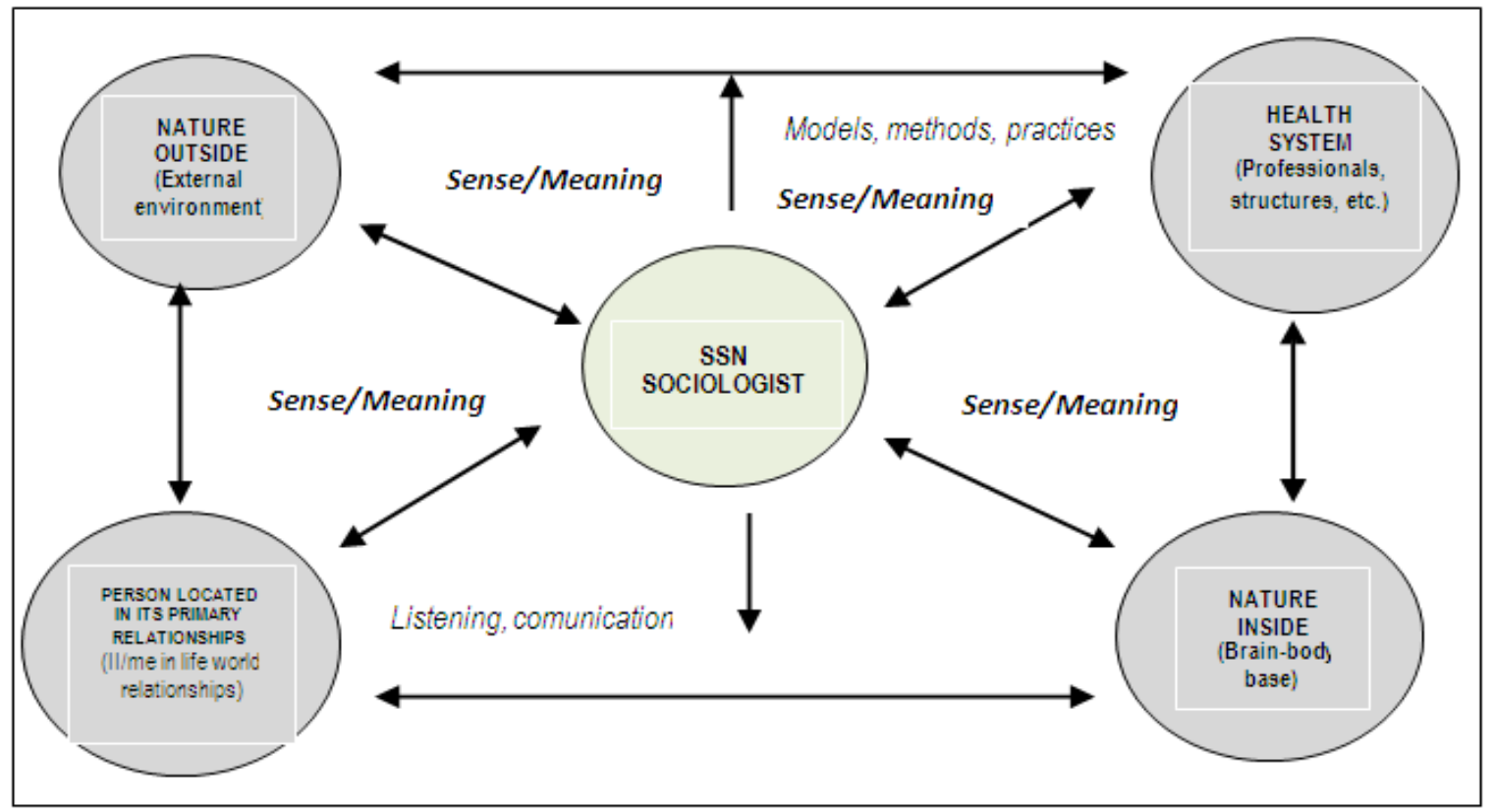

Figure 3. The Sociologist as Systemic Catalyst in the sense of Interprofessionality within the SSN 
Our original outline of a theoretical framework in which sociologists occupy a myriad of positions and play a number of roles within mental health and addiction services, works well when applied to this pilot study, conducted specifically through qualitative analysis of interviews between SSN sociologists working in the regions of Emilia-Romagna ( 9 sociologists) and Calabria (8 sociologists). The SSN sociologist emerges as the "glue" of interprofessionality because, compared to other more prominent health professionals, The Professional Sociologist has a more favorable set of critical and methodological skills in terms of improving health and social integration practices and in redesigning the pathways and practices of interprofessionalism.

The two areas of inter-professionalism (Clinical and Exercise, Government and Government-Exercise) seem to incarnate in the two intertwined souls of the Professional Sociologist we mentioned earlier. Both regularly re-emerged, albeit with different intensity in this study in relation to crises, conflict and alliances, development strategies, mental health services and addictions, both in Calabria and Emilia-Romagna.

In conclusion, this study reveals not only the new professional repositioning of Italian Professional Sociologists working within the SSN, but also describes the multiple roles these sociologists play in social and health care services as integrators of interprofessional and organizational action within the roles and realms of cross-sociological intervention. In future works we will report other details on this between-group behavior of Italian sociologist in healthcare [66].

\section{Acknowledgements}

We are very grateful to all the participants and to DELPHI. Many thanks also to the Board of Directors of SISS, especially past President Carmine Clemente, University of Bari, and current President Franco Toniolo. For information on SISS activities and publications visit the organizations website: http://www.sociologiadellasalute.com/ Last, but not least, special thanks to Erica Hansen for her translation assistance.

\section{REFERENCES}

[1] W. Tousijn, V.B.M. Giorgino .The complexities of negotiating governance change: introducing managerialism in Italy. Health Economics Policy and Law, Vol.4 (S3), July, 329-346, 2009.

[2] W. Tousjn. Integrating health and social care: Interprofessional relations of multidisciplinary teams in Italy. Current Sociology, vol.60, 4, 522-537,July 2012.

[3] S.A. Nancarrow, A.M. Borthwick (2005). Dynamic professional boundaries in the healthcare workforce.
Sociology of Health and Illness, Vol.27,7, 897-919, November 2005.

[4] A. Ardigò. Crisi di governabilità e mondi vitali [Crisis of Governance and Life Worlds]. Cappelli, Bologna, 1980.

[5] R. Brampton, C. Cowton. The E-Interview. Forum Qualitative Social Research, Vol.3,2, May 2002.

[6] H. J. Steadman. Boundary spanners: A key component for the effective interactions of the justice and mental health systems. Law and Human Behavior, Vol. 16,1, 75-8, February 1992.

[7] G. Budrys. Coping with change: physicians in prepaid practice. Sociology of Health and Illness, Vol.15, 3,353-374, 1993.

[8] A.B. Flood, M.L. Fennel. Through Lenses of Organizational Sociology: The Role of Organizational Theory and Research in Conceptualizing and Examining Our Health Care System. Journal of Health and Social Behaviour, extra issue, 154-169, 1995.

[9] P. Williams. The competent boundary spanner. Public Administration, Vol. 80, 1, 103-124, 2002

[10] A. Lo Scalzo, A. Donatini, L.Orzella, A.Cicchetti, S. Profili, A.Maresso. Italy: Health system review.Health Systems in Transitions, Vol.11, 6, 1-216,2009.

[11] G. Turati. The Italian Servizio Sanitario Nazionale: A Renewing Tale of Lost Promises, Costa-Font J. Et al. Eds., Federalism and Decentralization in European Health and Social Care, Palgrave-Macmillan Pub.Ltd., pp.47-66, 2013

[12] A. Maturo. Italy: Healthcare Delivery System. The Wiley-Blackwell Encyclopaedia of Health, Illness, Behavior, and Society, Wiley-Blackwell, Oxford, 2014.

[13] H. Aungust, M. Ruhe, K.C. Stange. Boundary spanning and health: invitation to a learning community. London Journal of Primary Care, 4,109-115, 2012.

[14] M.B. Kousgarrd, A.S. Kjær Joensen, T. Thorsen. The challenges of boundary spanners in supporting inter-organizational collaboration in primary care - a qualitative study of general practitioners in a new role. BMC Family Practice, Vol.16, 17, 2015.

[15] N. Meier. Collaboration on Healthcare Trough Boundary Work and Boundary Objects. Qualitative Sociology Review, Vol. XI, 3,60-82, 2015.

[16] F. Pansa, a cura di. La professione del sociologo nel Servizio Sanitario Nazionale. Una risorsa innovativa e strategica per la governance della salute [The Profession of sociologist in National Healthcare Service] Franco Angeli, Milano,2009.

[17] G. Bertin. Welfare regionale in Italia [Regional welfare in Italy], Edizioni Ca'Foscari,Venezia,2012.

[18] G.Bertin. La governance ibrida] [Hybrid Governance], Studi di Sociologia, Vol. 3, 249 280,2009.

[19] G.Bertin. Modelli di welfare e sistemi sanitari: quali omogeneità e specificità?[Welfare Models and Healthcare System: such as homogeneity, such specificity], Salute e Società, a.XI, Vol.1,2012.

[20] C. Cipolla, E.Minardi, R.Sutter, G.Burani, G. Pelliciari.Il sociologo nel Servizio sanitario nazionale [The Sociologist in the Italian Healthcare System], Franco Angeli, Milano, 1983. 
[21] W.Orsi.Il sociologo sanitario nel SSN italiano [The health sociologist in the Italian SSN]. Salute e Società, a.III, Vol.3, 39-51, 2004.

[22] R.Siza. Le professioni del sociologo [The Professions of sociologist], Franco Angeli, Milano, 2006.

[23] R.Siza. La professione del sociologo tra sviluppo e diffusione della Sociologia [The Profession of sociologist between development and dissemination of Sociology]. Sociologia Italiana (AIS Journal of Sociology), Vol.1, April,167-181,2014.

[24] G. Montanari, P.Ugolini,Il sociologo del Ser.T. come esperto dei processi comunicativi relazionali nella prevenzione del disagio giovanile (e delle tossicodipendenze)[the sociologist in Addiction service ...] .In SoIS, a cura di, Meridiana Tossicodipendenze, Centro Culturale San Biagio, Cesena,91-101, 5 ottobre 1992

[25] P. Ugolini,a cura di. Qualità e Outcome nelle dipendenze [Quality and Outcome in Dependencies]. Dibattito europeo e italiano, esperienze in Emilia Romagna. Franco Angeli, Milano, 2005.

[26] SISS (Società Italiana di Sociologia della Salute, Italian Society of Health Sociology) ed., Essere e fare il sociologo in sanità $[\mathrm{Be}$ and do Sociologist in the Healthcare].Salute e Società, a.VII, Supl. al Vol.3, Franco, Angeli, Milano, 2009.

[27] E. Minardi. Essere e fare il sociologo della salute oggi [Be and do health sociologist today], Salute e Società, a.VIII- Suppl. al n.3,67-82, 2009 .

[28] L. Luison, Ed. Introduzione alla Sociologia Clinica [Introduction to Clinic Sociology], Franco Angeli, Milano, 1998

[29] I. Rende, I. Sociologia professionale e salute [Professional sociology and Health]. in R. Palidda, R. ed. Fare Sociologia. Paradigmi conoscitivi ed esperienze sul campo, n.4, pp. 145-174; Guerini studio: Milano, 2002.

[30] S. Cifiello, G. Gosetti, E. Minardi.Il sociologo nelle ASL: comunicazione e prevenzione. [The sociologist in Local Health Authorities: communication and prevention].Salute e Società, A. II, Vol. 3, 2003, 1-19.

[31] A. Perino. La pianificazione socio-sanitaria: ruolo e funzione del sociologo della salute [The Social and Health Planning: Roles and Functions of health sociologist].Salute e Società, A.VII.,Suppl. Al n.3, 116-130,2009.

[32] A. Perino. La Professione del Sociologo", Unitn., a.XIV, 132, novembre-dicembre 2012

[33] Guzzo,P.P. Il sociologo territoriale nella prospettiva di Sainsaulieu: interprofessionalità e reti sanitarie aggrovigliate. [The territorial sociologist in Sainsaulieu perspective: interprofessionality and entangled health net].Salute e Società, a.VIII- Suppl. al n.3, pp.161-166, 2009.

[34] G. Bertin. Recensione-Francesco Panza (a cura di, 2009), La professione del sociologo .... [review-F.Pansa The (ed.2009), The Profession of Sociologist...], Salute e Società, a. IX, n,2, 203-204, 2010

[35] D. Galesi. Quali competenze e percorsi didattici per una maggiore efficacia formativa della laurea in sociologia? Uno studio esplorativo con metodologia Delphi. [What skills and educational patterns for a major efficacy of Degree in
So-ciology? An exploratory study with Delphi methodology] In A. Perino, L.Savonardo (a cura di).Sociologia, professioni e mondo del lavoro, Egea, Milano,175-191, 2015.

[36] A. Perino, L.Savonardo (a cura di).Sociologia, professioni e mondo del lavoro [Sociology, professions, and labour market], Egea, Milano, 2015.

[37] P.P. Guzzo, A. Fiorita, S. Grande. Gli Osservatori provinciali per le tossicoalcoldipendenze in Calabria. Buone prassi di osservazione tra Cosenza e Catanzaro. [The Provincial Observatories of Dependencies in Calabria. Good Practices of Observation between Cosenza and Catanzaro].In P. Ugolini, ed, Alcol e buone prassi sociologiche. Ricerca, osservatori, piani di zona, clinica[Alchol and Good Sociological Practices.], Franco Angeli, Milano, 2013.

[38] L. Benvenuti. Il ruolo e l'importanza delle conoscenze e delle pratiche sociologiche in campo terapeutico. Elementi di Socioterapia [The role and importance of sociological knowledge and practices in the therapeutic field. Elements of Social Therapy], Meridiana, Cesena, 1992.

[39] L.Benvenuti.Malattie Mediali. Elementi di socioterapia [Media diseases. Elements of Social Therapy], Baskerville, 2002.

[40] D'Amour P. , Oandasan I. Interprofessionality as the field of interprofessional practice and interprofessional education: an emerging concept. Journal of Interprofessional Care. Vol.19,1,8-20, 2005

[41] Ardigò A.Società e salute.[Society and Health] Franco Angeli, Milano, 1997.

[42] Ardigò, A. Audizione 12a Commissione del Senato- IX legislatura, Resoconto stenografico, 15-16, 18 gennaio 1984 [Hearing of $12^{\text {th }}$ Italian Senate Commission- IX legislature, January $\left.15^{\text {th }}, 16^{\text {th }}, 18^{\text {th }}, 1984\right]$.

[43] Sainsaulieu I. Il coinvolgimento del sociologo nel suo oggetto: il caso del lavoro sociale, sanitario e di cura [The involvement of sociologist in its object: the social, health, cure work]. Salute e Società. a.VII-Supl. al n.3, 113-148,2009.

[44] SoIS (Società Italiana di Sociologia), a cura di. Meridiana Tossicodipendenze, Centro Culturale San Biagio, Cesena, 91-101, 5 ottobre 1992.

[45] Saponaro A., Ugolini P., Osservatiorio dipendenze: sistema informativo, valutazione, ricerca, qualità [Observatory of Dependencies: Information system, Assessment, Research, Quality]. Salute e Società, a.VIII- Suppl. al n.3, 35-57, 2009.

[46] B. Hudson. Interprofessionality in health and social care: the Achilles' heel of partnership?.Journal of Interprofessional Care.Vol.16, n.1,7-17, 2002.

[47] H. Donohe, Stellefson M., B. Tennant. Advantages and Limitations of the e-Delphi Technique: Implications for Health Educationa Researchers. American Journal of Health Education. Vol.43. no.1, January/February 2012.

[48] S. Kvale. Interviews: An Introduction to qualitative research interviewing. Sage, Thousand Oaks, Californa, 1996.

[49] J.Salmons. Qualitative on line interviews ( $2 n$ ed.).Thousand Oaks, A:Sage Publications Inc.2015.

[50] James N., Bushes H. Credibility, authenticity and voice: Dilemmas in online interviewing. Qualitative 
Research,Vol.6,n.3,403- 420,2006.

[51] Morgan S. J., Symon, G.Electronic interviews in organizational research. In: C. Cassell, G. Symon Eds., Essential guide to qualitative methods in organizational research. Sage, London, 2004.

[52] Milne E. Letters, postcards, e-mail: Technologies of presence. Routledge, New York, 2010.

[53] Delbecq A. L., VanderVen A.H. A Group Process Model of Problem Identification and Program Planning. Journal Of Applied Behavioral Science; VII, July/August, 466-91, 1971.

[54] Delbecq A.L, VanderVen A.H., Gustafson D.H. Group Techniques for Program Planners, Scott Foresman and Company, Glenview (Ilinois), 1975.

[55] E. Bruggen, P. Willems. A Critical comparison of offline focus groups, online focus groups and e-Delphi. International Journal of Market Research, vol.51,3, 363-381, 2009.

[56] Chou, C. (2002). Developing the e-Delphi system: A web-based forecasting tool for educational research. British Journal of Educational Technology, 33(2), 233-236

[57] C.Bezzi. Il Disegno della ricerca valutativa [The Design of Evaluation Research].Franco Angeli, Milano, 2001.

[58] W.L. Neuman. Social Research methods: Quantitative and Qualitative approaches (5 $5^{\text {th }}$ ed.), Boston: Allyn and Bacon. 2000.

[59] V. Braun, V. Clarke. Using thematic analysis in psychology.
Qual Res Psychol.Vol.3:77-101, 2006.

[60] M.M. Huberman. Qualitative Data Analysis. An Expanded Sourcebook, $2^{\text {nd }}$ ed. London, Sage, 1994.

[61] M. Q. Patton. Qualitative Research \& Evaluation Methods. 3rd ed. Thousand Oaks, California: Sage; 2007.

[62] P. Lindqvist, U. K.. Nordänger. (Mis- ?) using the E-Delphi Method: An Attempt to Articulate the Practical Knowledge of Teaching Journal of Research Methods and Methodological Issues. Vol.1, 1, 2007.

[63] M. Turoff, S.R. Hiltz. Computer based Delphi processes. In M. Adler \& E. Ziglio (Eds.), Gazing into the oracle: The Delphi and its application to social policy and public health. London, England: Jessica Kingsley, 1996.

[64] P. Lugosi, H. Janta, P. Watson.Investigative management and consumer research on the internet. International Journal of Contemporary Hospitality Management, Vol. 24, 6, pp. 838-54, 2012.

[65] Maturo A. La produzione comunicativa sanitaria e le sue conseguenze sociali: il sociologo come mediatore di senso", [Health communication and its social consequences: the sociologist as a "meaning mediator"], in La spendibilità del sapere sociologico, a cura di Costantino Cipolla, Angeli, Milano, 2002.

[66] J. Braithwaite. Between-group behaviour in healthcare: gaps, edges, boundaries, disconnections, weak ties, spaces and holes. A systematic review. BMC Health Services Research,Vol.10,330, 2010. 